\title{
Socioeconomic determinants of organic cotton adoption in Benin, West Africa
}

\author{
Epiphane Sodjinou ${ }^{1 *}$, Laurent C Glin ${ }^{2}$, Gian Nicolay ${ }^{3}$, Silvère Tovignan ${ }^{4}$ and Jonas Hinvi ${ }^{5}$
}

\author{
* Correspondence: \\ sodjinoue@gmail.com \\ ${ }^{1}$ Ecole Nationale des Sciences et \\ Techniques Agronomiques de \\ Djougou, Université de Parakou, 03 \\ BP 412, Porto-Novo, République du \\ Benin \\ Full list of author information is \\ available at the end of the article
}

\begin{abstract}
Organic cotton relies on ecological processes and the use of natural resources to sustain the production system, unlike conventional cotton, mainly characterized by massive utilization of synthesis chemicals. In West Africa, where rural livelihoods are particularly vulnerable, organic cotton is expected to contribute not only to poverty reduction but also to strengthen households' resilience. The objective of this study was to assess institutional and socioeconomic factors determining farmers' decisions to adopt organic cotton. For this purpose, we applied a probit model on empirical data collected from producers of the Centre and the Northern parts of Benin. Overall, we found that organic cotton adoption is mainly determined by farmers' socioeconomic characteristics, the physical distance between farm and house, and contact with extension and advisory services. Organic farming is more attractive to women compared to conventional farming. This because such type of cotton farming enables women to hold a separate cotton farm and thus increase their economic independence, whereas with the conventional system they depend mainly on the farm of the (male) head of the household. Older, less educated and low-income farmers who express environmental concern are more likely to adopt organic cotton. Subsequently, organic cotton should be considered as a prospective policy option to reach the poor and strengthen their livelihoods conditions while contributing to preserve the environment and natural resources. Furthermore, farmers who have their farm near home are more likely to adopt organic farming than those who have the farm far from their home. It also came out that organic farmers have more contacts with advisory and extension services. Finally, the study noted that there is still a need to enhance the extension system by: (1) exploring, designing, and upgrading innovative pedagogic tools such as videos and mobile phone technology to foster learning; and (2) strengthening organic farmer's organizations and the linkage with agricultural research organizations for technology development.
\end{abstract}

Keywords: Organic farming adoption; Low-income farmer; Gender; Probit; Benin

\section{Background}

Cotton plays a significant economic role for many countries of West Africa. Indeed, in addition to its contribution to the GDP and to total merchandise exports (from $25 \%$ to $45 \%$ ), this sector represents more than half the income for roughly two millions of households in West Africa (Baffes 2007; Moseley and Gray 2008). Despite this economic importance, cotton is a controversial crop, which is at the centre of debates on globalization, structural adjustments, food security, biotechnology, agricultural

\section{Springer}

(c) 2015 Sodjinou et al.; licensee Springer. This is an Open Access article distributed under the terms of the Creative Commons Attribution License (http://creativecommons.org/licenses/by/2.0), which permits unrestricted use, distribution, and reproduction in any medium, provided the original work is properly credited. 
subsidies, poverty alleviation, and sustainable development (Moseley and Gray 2008). In particular, Benin is among the countries most dependent on cotton (Gergely 2009). In fact, cotton accounts for $40 \%$ of foreign exchange earnings, employs $45 \%$ of rural households, and provides income to more than one third of the population (MAEP 2011). Accordingly, the Government of Benin gave a significant place to this sector in its development strategy as a tool for poverty alleviation.

For long, the cotton sector was governed by a parastatal company called SONAPRA (Société Nationale pour la Promotion Agricole) which had the monopoly over most of the commercial roles relating to cotton production, such as purchase and distribution of seeds and fertilizers as well as pesticides, direct purchasing of cotton from the farmer, and determination of price (Kütting 2004). But, since the beginning of the 1990s the sector has undergone some reforms including the privatization of input supply, introduction of private ginners and creation of interprofessional bodies to take over the sector management, through a highly regulated system precluding competition among ginners (Gergely 2009). However, during the last three years the new institutional arrangement collapsed due to a number of crises that resulted in distrust and mistrust between the government and the private stakeholders (Glin 2014). Despite all the upheavals and changes experienced by the sector, the method of production of conventional cotton has remained virtually unchanged with a strong use of synthetic chemical inputs.

Indeed, in order to obtain high quality and competitive cotton fiber on international market, producers are encouraged to use extensively mineral fertilizers and synthesis chemical pesticides. This was particularly encouraged by structural adjustments and neoliberal policies that stressed agricultural intensification as a strategy to achieve food security and poverty alleviation (Glin et al. 2012). In addition to official chemical inputs, other pesticides banned in Benin, including lindane and dieldrin, are smuggled from Nigeria and illegally used in cotton production (Pazou et al. 2006a). Many of these official or illegally used chemical products have adverse effects on environment and both the human and animal health. For instance in 2000, 147 persons were poisoned by cotton pesticides of which 10 fatalities (OBEPAB 2002). In certain localities, the cotton farms are located near rivers and pesticides could "distribute among the river ecosystem components, such as water and sediment, and accumulate in biota" (Pazou et al. 2006b).

This context came together with international developments (e.g., the 1992 United Nations Conference on Environment and Development) targeting environmental issues and created a favorable situation for alternatives to the conventional farming system (Glin et al. 2012). Taking advantage of this context, OBEPAB (Organisation Béninoise pour la Promotion de l'Agriculture Biologique) with the support of international and national networks introduced organic cotton production in Benin in the mid-1990s as an alternative to address the above mentioned problems. Currently, other organizations including Helvetas Swiss Intercooperation-Benin are active in the organic cotton sector in Benin.

The organic cotton relies only on ecological processes and the use of natural resources. It could increase the income of poor farmers through higher sales prices. One important requirement of the organic production is the certification, which entails a regular and effective control and auditing of the production and processing practices to verify and ensure the traceability of the organic products and the compliance with 
the international organic standard. The cost of certifying smallholdings of organic farmers, particularly in developing countries, favors certification at the level of farmer groups or cooperatives, instead of individual farmers (Glin et al. 2013: 549, see also Lockie et al. 2006; Ton et al. 2007).

In West Africa, where rural livelihoods are particularly vulnerable, organic cotton is expected to contribute not only to poverty reduction but also to strengthen households' resilience (Glin et al. 2013). Furthermore, given its ability to improve soil fertility (soil structure, biological activity, etc.), the risk of loss of production is relatively low in organic farming (Hulsebusch et al. 2007). Besides, several studies proved that organic cotton is more profitable than conventional cotton (e.g., Gbesso 2000; Pacini et al. 2002; Matthess et al. 2005; Eyhorn et al. 2007), provides benefits regarding biodiversity (Hole et al. 2005) and climate protection (Skinner et al. 2014).

However, the development of organic cotton has some drawbacks, including the structural difficulties (both actual and perceived) of doing business in sub-Saharan Africa; lack of transport or difficulties to transport organic fertilizer, a shortage of export oriented knowledge (Ferrigno et al. 2005). Furthermore, the development of organic cotton in most sub-Saharan African countries is enhanced by projects funded by Western donors (Ferrigno et al. 2005; Justus 2009).

Despite these shortcomings, the production of organic cotton has experienced significant growth over the past decade, moving from 185.2 tons during the 2002-2003 agricultural campaign to 824.3 tons in 2011-2012, representing an annual increase of about 34.5\% (Figure 1) $)^{\mathrm{a}}$. Currently around 2,500 farmers are engaged in organic cotton production, gaining approximately USD 600,000 as export value for Benin economy. Moreover, during the last five years the organic cotton chain is undergoing a progressive transformation from an experimental, small-scale and donor-dependent initiative towards a market-oriented, large-scale and self-financing transnational commodity network (Glin et al. 2012). The growth of the organic cotton sector eventually convinced the Government to target organic cotton in Benin's Agriculture Sector Development Plan (MAEP 2011). Over the past two agricultural campaigns, the Government through SONAPRA (a state owned company) was also engaged in the marketing of the organic cotton.

Unfortunately, like in most developing countries, very few data are available on organic farming in Benin and West Africa (Kristiansen et al. 2006). In particular, there

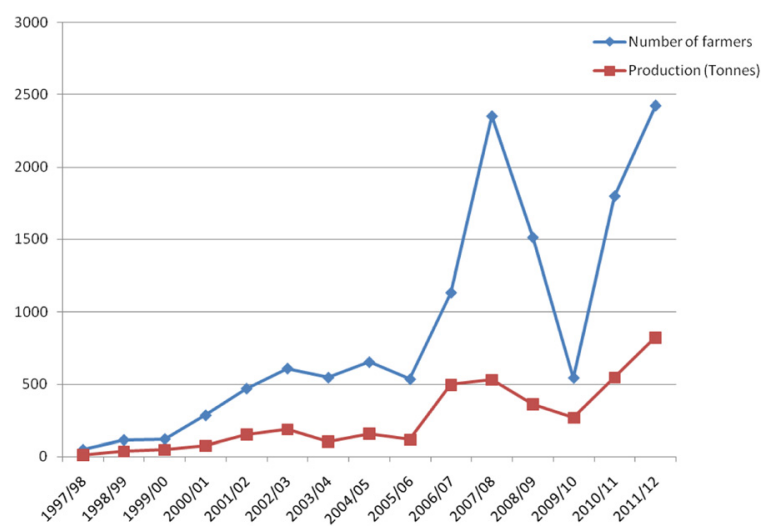

Figure 1 Trends of organic cotton production in Benin (OBEPAB, 1996-2012). 
are very few studies that investigated farmers' decisions to adopt organic cotton in West Africa. Thus, this study aims to contribute to the understanding of factors underlying farmers' decision to adopt organic cotton, based on empirical data collected from producers of the Centre and the Northern parts of Benin. In other words, the objective of this study is to assess institutional and socioeconomic factors influencing the adoption of organic cotton in Benin. The identification of factors promoting or hinder the adoption of organic cotton can help to better define policy options and strategies for further dissemination of this type of cotton farming.

The remainder of the paper is organized as follows. The second section, related to data and methods, begins with the description of the sampling and data collection techniques, and then outlines the analytical framework. The results and discussion section (section 3) starts with a descriptive analysis of data collected on conventional and organic cotton producers, and ends with the results of the probit model, interpreted, and discussed in three sub-sections. The fourth section concludes and provides the policy implications of our findings.

\section{Methods}

\section{Sampling and data collection}

The study was carried out in the Republic of Benin, a tropical West African country situated between the 1st and 4th Meridian of longitude and between the 6th and 12th parallels of north latitude. Data were collected, during the agricultural campaign 2012-2013, from three research sites of the Project SYPROBIO (SYstèmes de PROduction BIOlogique diversifiés), a EU funded regional and multi-stakeholder research project involving national research organizations, farmers' organizations, and Helvetas Swiss Intercooperation. The project promotes farmer-driven innovations to address food security, poverty alleviation and resilience to climate change. The project is led by FiBL (Research Institute of Organic Agriculture) and is implemented in Benin, Burkina Faso and Mali.

The first of our research sites is located in the Centre of Benin, one of the largest cotton production areas with a low pressure on land $\mathrm{d}^{\mathrm{b}}$. The second site, Northeast of Benin, belongs to the oldest and largest cotton zone of Benin and is characterized by a high pressure on land. The third site is in Northwest-Benin, a marginal zone of cotton production with also a high pressure on land. In each of the three categories of areas, a village were selected, taking into account criteria such as the coexistence of organic farming (certified) and conventional cotton farming, the year of introduction of organic cotton (at least 3 years) and physical accessibility in all seasons of the year. Thus, Aklampa in Glazoué District, was selected for the Centre of Benin, Bonhanrou (District of Banikoara) for the Northeast-Benin, and Batia (in Tanguieta District) for the Northwest-Benin (cf. Figure 2).

At each site we made a census of all households and then classified these households into four classes (rich, medium, poor, very poor) according to the Wealth Ranking approach (Ranjani et al. 2008). The Wealth Ranking was carried out using, for each site, five key-informants who have a thorough understanding of the socio-cultural and economic context of the site. It is worth noting that our wealth ranking approach primarily accounts of the living conditions of the household as a whole and does 


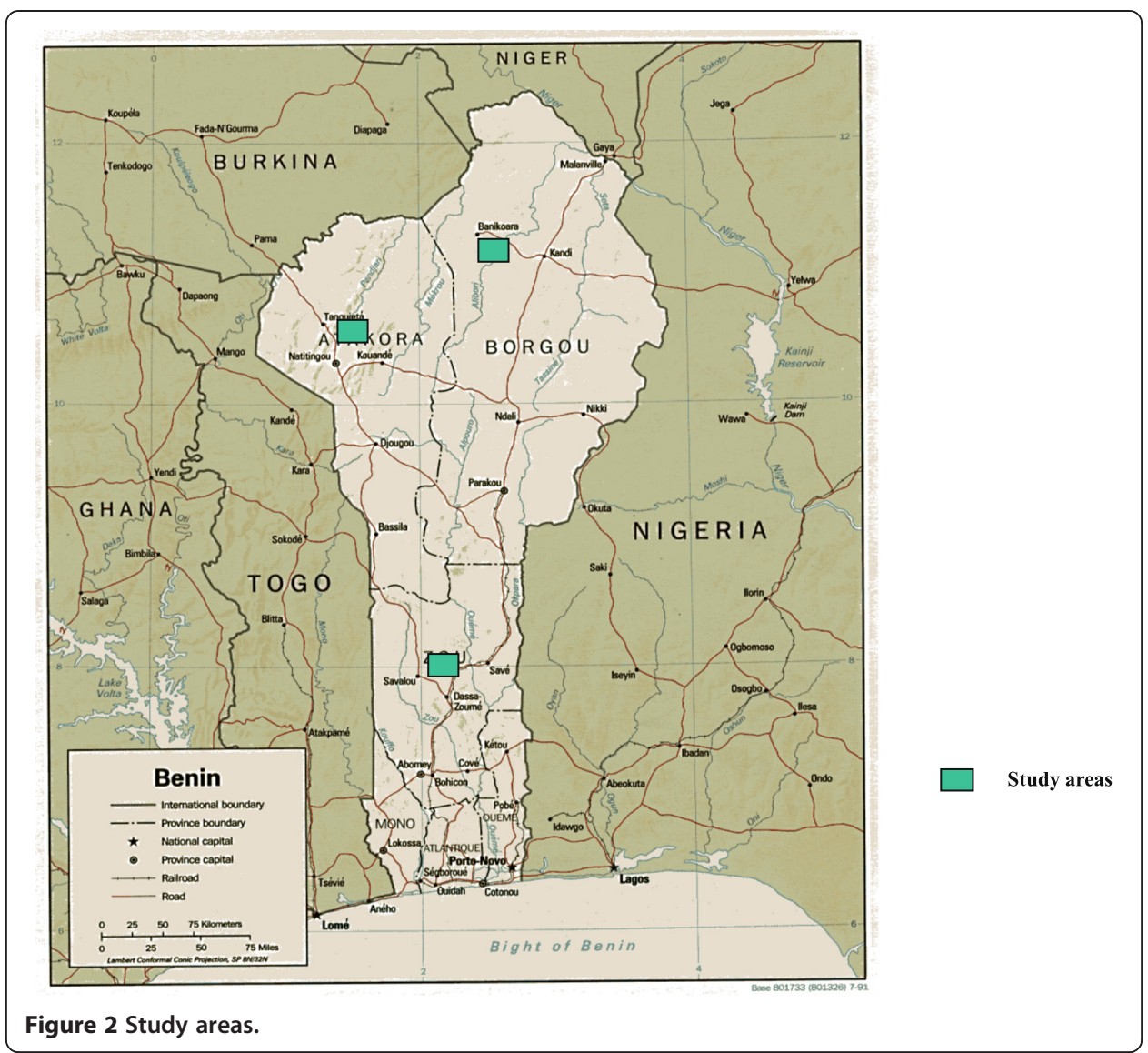

not discriminate individual members (be it household head or not, man or woman) within household. We assume that all individual members within a household share the same livelihood conditions. Thus, they are attributed accordingly the same wealth ranking score.

About 81 households were selected at each site. The number of households selected in each (wealth) class is based on a quota defined by the formula: $q=n / N$, with $N$ the number of households identified in the village, $q$ the sampling coefficient and $n$ (with $n \approx 81$ ) the total number of households to be selected in the village (Table 1). For each (wealth) class with $n_{i}$ households, the number of members selected was obtained as followed: $\left(q \times n_{i}\right)$. These households were randomly selected using random numbers generated with Microsoft Excel software.

Table 1 Distribution of the sampled farmers per research site

\begin{tabular}{lllll}
\hline Class & \multicolumn{2}{l}{ Research site } & & Total \\
\cline { 2 - 5 } & Batia & Bonhanrou & Aklankpa & 30 \\
\hline Rich & 12 & 4 & 14 & 47 \\
Medium & 13 & 7 & 27 & 104 \\
Poor & 28 & 50 & 26 & 61 \\
Very poor & 28 & 22 & 11 & 242 \\
Total & 81 & 83 & 78 & \\
\hline
\end{tabular}


Finally, in each sampled households, all member producing cotton were interviewed separately.

\section{Analytical framework}

The model used

We assume that the decision to adopt or not to adopt organic cotton is voluntary and that the differences in responses at the household level are often due to the fact that producers have, e.g., different cultures, different levels of education, different endowments in resources, different constraints, different farming objectives and preferences, and experience different socio-economic conditions. As consequence, some farmers will adopt and others will not, depending upon the utility they expect from the innovation (the organic farming). In other words, let $U_{i}^{a}$ be the expected utility that a given farmer $i$ would receive from adopting the organic cotton and $U_{i}^{b}$ the expected utility gained from using the alternative, i.e. conventional cotton. "The observed choice between the two reveals which one provides the greater utility" (Greene 2008: 777). Hence, farmers adopt organic cotton if the utility they expect to obtain $\left(U_{i}^{a}\right)$ by adopting this activity is higher than what they would have if they adopt conventional cotton $\left(U_{i}^{b}\right)$, i.e. if $\left(U_{i}^{a}>U_{i}^{b}\right)$. Following Greene (2008: 777), a common formulation is the linear random utility model,

$$
U_{i}^{a}=x_{i}^{\prime} \beta_{a}+\varepsilon_{i a} \text { and } U_{i}^{b}=x_{i}^{\prime} \beta_{b}+\varepsilon_{i b}
$$

Following Verbeek (2004: 192), for each farmer $i$, we can write the utility difference between adoption and non-adoption as a function of observed characteristics $\left(x_{i}\right)$ and unobserved characteristics $\left(\varepsilon_{i}\right)$, i.e.:

$$
y_{i}^{*}=U_{i}^{a}-U_{i}^{b}=x_{i}^{\prime} \beta+\varepsilon_{i}
$$

with $y_{i}^{*}$ a latent variable which is not observable, and $\beta=\beta_{a}-\beta_{b}$. Models, often derived from equation 1 , determine the probability that farmers adopt organic cotton $\left(y_{i}=1\right)$. In practice, the probit or logit models are used to determine the probability that $y_{i}=1$. The probit is based on standard normal distribution while the logit is based on standard logistic distribution. According to Greene (2008), these two models often lead to the same conclusion and it is difficult to make a choice between the probit and the logit on theoretical bases.

In this study, the probit model was used and is given by the following formula (Greene 2008: 773):

$$
\operatorname{Prob}\left(y_{i}=1 \mid x_{i}\right)=\int_{-\infty}^{x^{\prime} \beta} \phi(t) d t=\Phi\left(x_{i}^{\prime} \beta\right),
$$

where, $\phi(\cdot)$ and $\Phi(\cdot)$ correspond respectively to the density function and the cumulative distribution function of the normal distribution. The dependent variable is the adoption status of the producer, with 1 for farmers who adapt organic cotton, and 0 for farmers who do not adopt it.

\section{Hypothesized factors influencing organic cotton adoption}

There are several models or paradigms employed in the literature to explain the decision of smallholder farmers to adopt new technologies (Negatu and Parikh 1999; 
Moumouni et al. 2013). We identified here four models: (1) the technology diffusion model that considers the characteristics of technology as determinants of adoption (e.g., Sarker and Itohara 2008); (2) the economic constraints model, which emphasizes the importance of economic and institutional factors in the adoption of technology (e.g., Bolwig et al. 2009); (3) the technology user's context model that posits that farmers' characteristics and subjective perceptions of technology influence adoption (e.g., Sarker and Itohara 2008) and (4) the integrated model that combines the features of the three above models. For this integrated model five categories of factors may influence farmers' decision to adopt a given innovation or technology (e.g., Chilonda and van Huylenbroeck 2001; Sodjinou 2011). These include characteristics specific to farmers and their households (e.g. age, knowledge, motivation/objective), characteristics related to their farm (land available, labor, water, etc.), biophysical factors (diseases/parasites, climatic factors, etc.), institutional factors (contact with extension services, access to credit, information sources, government agricultural policy, etc.) and economic factors (e.g. markets and prices of outputs and inputs). We adopted this model to capture the complexity of organic farming and related adoption factors. Accordingly, we used the following explanatory variables in our probit model (Table 2):

- the age of the farmer (AGE). The relationship between farmers' age and the decision to adopt an innovation or technology is not clear in the literature. Indeed, some authors found that older farmers are more likely to adopt an innovation, while others found that young people are open to adopt new technologies (Rogers 2003). Thus, in this study, we expect that the sign of the variable AGE can be positive or

Table 2 Variables used in the probit model with expected sign on organic cotton adoption

\begin{tabular}{|c|c|c|}
\hline Variable & Label & $\begin{array}{l}\text { Expected } \\
\text { signs }\end{array}$ \\
\hline AGE & Age of the producer (year) & $+/-$ \\
\hline AGE2 & Square of AGE (years ${ }^{2}$ ) & $+/-$ \\
\hline SEX & Sex of the producer ( $1=$ male, $0=$ female) & + \\
\hline EDUC & Formal education of the producer (year) & + \\
\hline EXPCOT & Experience in cotton production in general (year) & $+/-$ \\
\hline CLASSP & Class of poverty as perceived by producers ( $1=$ very poor, $2=$ poor, $3=$ medium, $4=$ rich $)$ & - \\
\hline CENTRE & Regional dummy ( 1 = Farmers located in the Centre of Benin, $0=$ otherwise) & $+/-$ \\
\hline NORTHW & Regional dummy ( 1 = Farmers located in the northwest-Benin, 0 = otherwise) & $+/-$ \\
\hline DISTEX & Distance between the producer's house and his farm (km) & $+/-$ \\
\hline DISTEX2 & Square of DISTEX $\left(\mathrm{km}^{2}\right)$ & $+/-$ \\
\hline HHSIZE & Household size (number of members) & + \\
\hline SUPTOT & Amount of land available in ha & $+/-$ \\
\hline OXEN & Ownership of oxen (1 = yes) & + \\
\hline DISTM & $\begin{array}{l}\text { Distance between the village and the nearest market place where the producer sells its } \\
\text { products }(\mathrm{km})\end{array}$ & - \\
\hline ACRED & Obtained credit ( $1=$ yes, $0=$ no $)$ & - \\
\hline COOP & Membership of producers' organization ( $1=$ yes, $0=$ no) & + \\
\hline NVISIT & Contact with extension agents (number of visits between January and October 2012) & + \\
\hline
\end{tabular}


negative. Besides, Sodjinou (2011: 36) argued that producers might be opened to new technologies until a certain age after which they become less open until they reach old age. The opposite may also occur in some cases. Accordingly, in order to allow this nonlinear relationship, we include the square of the farmers' age in the adoption model;

- the gender of the producer (SEX), with 1 for male and 0 for female. We used the gender of the producer rather than the gender of the household head, the conventional practice in most adoption studies. Indeed, in cotton production regions of Benin, it is not common to find adult men in female-headed households, while male-headed households may include one or many women. However, adopting the gender of the household head could be dismissive of the reality at individual level. In fact, decisions made within households depend upon the characteristics of each producer rather those of the household head (Doss et al. 2003), particularly as far as the adoption of organic cotton is concerned. In the Sub-Saharan African context, sometimes the attitude and position of the household head regarding organic is different from that of the other members. Thus, the household head can adopt organic while some individual members can remain conventional and vice-versa. Therefore, the utilization of farmer's gender instead of the gender of the household head allows us to assess the behavior of female farmers regarding organic cotton adoption in female-headed as well as male-headed households. For Doss and Morris (2001), controlling for everything else, men and women farmers made the same adoption decisions. However, in rural areas of Benin, women often face problems in the adoption of new technologies due to the lack of time or funds and poor control over productive resources. Thus, the variable SEX is supposed to have a positive influence on the organic cotton adoption, meaning that male farmers will be more likely to adopt organic cotton than female producers;

- year of schooling (EDUC). Educated producers are able to read manuals and other extension materials. They also have easily access to information, particularly through the media and can communicate easily with extension services. Education may also enhance farmers' ability to efficiently allocate inputs across competing uses and to gain more knowledge about adverse effects of conventional cotton farming (see Polson and Spencer 1991). For this reason, we expect that education will have a positive effect on the probability to adopt organic cotton;

- producers' experience in cotton farming in general (EXPCOT). Farmers' experience in cotton production can allow them to appreciate the advantages and disadvantages associated with this activity. Put differently, knowledge gained over time by farmers, from working in an uncertain and uncontrolled cotton production environment, may help in evaluating information, thereby influencing their adoption decisions (Sall et al. 2000). In addition, some producers who have spent several years in conventional cotton production can become accustomed or create/integrate networks that oblige them to continue conventional farming. Due to this relatively ambiguous situation, we expect that the effect of this variable on the adoption of organic cotton can be positive or negative.

- the poverty level of farmers' household (CLASSP), as identified by key informants through the wealth ranking, with values 1 (very poor), 2 (poor), 3 (medium) and 4 (rich). Rich farmers have as well more land as well as financial resources and can 
hardly manage the weeding without herbicides. Moreover, the issue of pesticides and mineral fertilizers is also financial because they represent a relatively high cost often difficult to be borne by the poor peasants (Guilmo et al. 2006). These poor farmers will be more likely to practice organic cotton farming than to rich farmers. Thus, we expect this variable to have a negative sign meaning that poor producers will be more likely to adopt organic cotton;

- regional dummies (variables CENTRE and NORTHW). As noted above, data were collected in three regions: Centre, Northeast and Northwest of Benin. These three regions are located in three different agro-ecological zones and have different socio-cultural realities. To account for this and to control for agro-climatic differences that could affect the household attitudes; we include two regional dummies in the probit model, namely the CENTRE, with 1 for farmers from the Centre of Benin and 0 otherwise, and the NORTHW, with 1 if the farmer is located in the Northwest-Benin and 0 otherwise. The Centre of Benin (notably Glazoué) is a region with low human pressure on agricultural land while the two other regions (notably Tanguiéta and Banikoara) experience high land pressure. Thus, the variable CENTRE also controls for pressure on land. The pressure on land in addition with socio-cultural variability and agro-climatic conditions inherent to each research site can affect farmers' attitude toward organic cotton adoption. We expect that the variables CENTRE and NORTHW could have positive or negative signs;

- the distance ( $\mathrm{km}$ ) between producers' house and their farms (DISTEX). Producers who have their farm close to their house will have less difficulty to transport organic fertilizers and other inputs used in the organic cotton production. This means that peasants who have their farms close to their house will be more likely to adopt organic farming. However, farms closed to producers' houses are generally smaller in size, reducing thus the possibility to practice some cropping systems strongly encouraged in organic agriculture such as crop rotation and inter-cropping. In such a condition, producers who have their farms far from their houses would be more likely to practice organic cotton. In short, we hypothesized that the sign of the variable DISTEX will be positive or negative. Furthermore, we introduced the square of DISTEX in our probit model in order to check whether there is nonlinearity in the relationship between organic cotton adoption and the distance between producers' house and their farm. In other words, we tested whether the relationship between the distance and the adoption of organic cotton is U-shaped or hill-shaped;

- household size (HHSIZE), i.e. the number of members in the household. The production of organic cotton is more labor-intensive than conventional cotton farming especially for transportation, application of organic inputs (pesticides, fertilizers, etc.) and weed control. This implies that the availability of labor will positively affect the adoption of organic cotton; this implies that this variable may have a positive sign;

- amount of land available (SUPTOT) in ha. According to the literature, smallholder farmers are more likely to adopt organic farming because they can easily mobilize the necessary organic inputs (particularly organic manure) and labor force for their small size of operation. The bigger the farm size the more difficult it is to appropriately handle organic farming. However, we may also predict that 
households with large land area could easily adopt certain practices of soil fertility improvement, such as inter-cropping, crop rotation, agro-forestry and improved fallow. Indeed, these technologies promoted in organic production require the mobilization of land for a certain period of time, which producers who have small land area cannot afford. In this regard, farmers who have large areas of land will be more likely to adopt these organic technologies. In light of the above, we expect that SUPTOT will have positive or negative signs;

- possession of oxen (OXEN), with 1 for producers who own oxen and 0 otherwise. Oxen are important means of tillage as they allow producers to sow large areas. The oxen also produce cow dung widely use as fertilizer in the production of organic cotton. Oxen can also help producers in the transport of organic fertilizers and other products necessary for the production of organic cotton. Therefore, possession of oxen may have a positive influence on the adoption of organic cotton;

- the distance (in $\mathrm{km}$ ) between producers' house and the nearest rural market (DISTM) where they use to sell their produce. At market places, farmers often interact with other producers and exchange on agricultural activities and technologies. These places can therefore foster discussion about the benefits of organic cotton and lead certain farmers to adopt this technology (Sodjinou and Henningsen 2012). Accordingly, we expect this variable to have negative sign, i.e. peasants living close to local market will be more likely to adopt organic cotton;

- access to credit (ACRED), with 1 for the producer who has obtained credit and 0 otherwise. In the literature, access to credit generally has a positive effect on innovations adoption. Indeed, having access to financial means allows producers to acquire the required inputs for the implementation of the new technology. However, the situation is different in the particular case of organic farming given the reliance on locally available resources instead of market-based inputs. Overall, organic farming is less dependent on credit than conventional farming. Besides, the measure of 'access to credit' often causes problems, i.e. this variable might be endogenous. To overcome this problem, Doss (2006) suggests including a measure of whether the farmer had ever received credit. However, this measure of access to credit is still not perfect, but it is a better measure of access to credit than the simpler question of whether the farmer used credit in the current period (Doss 2006). Accordingly, we use this approach in this study, and we expect that access to credit will negatively influence the adoption of organic cotton;

- membership of cotton producers' organization (COOP), with $1=$ yes and $0=$ no. Cotton producers' organization allows farmers to be in touch with their colleagues. This allows them not only to exchange with colleagues on new technologies but also to have access to agricultural inputs. These producer organizations and the meetings they organize are channels for the dissemination of innovations. So belonging to a producer organization is expected to have a positive influence on the adoption of organic cotton;

- contact with extension agents (NVISIT). Extension agents are sources of information on new agricultural technologies. Thus, we expect that farmers who have contact with extension agents will be more likely to adopt organic cotton. 


\section{Results and discussion}

\section{Farmers' involvement in cotton production}

Before analyzing the results of the probit model used in this study, it is important to mention that the proportion of households who continued with organic cotton since they converted is almost the same as for households that still grow conventional cotton. Stated differently, since the introduction of organic cotton in the mid-1990s, 38\% of households have finally adopted it, while $38 \%$ of households interviewed remained in conventional cotton (Table 3). Nearly 5\% of households have abandoned organic cotton of which about $3 \%$ returned to conventional cotton and $2 \%$ decided to no longer produce any type of cotton. In the same vein, among the households interviewed, $7 \%$ have never produced cotton while $9 \%$ produce both conventional and organic cotton (i.e. the husband produces the conventional cotton while the wife produces organic cotton, or vice versa). The latter corroborates the finding of Bassett (2010) for whom certain households commonly grow conventional cotton and organic cotton simultaneously, a practice forbidden by organic certifiers.

For all the interviewed producers, the major reasons for converting into organic cotton farming are mainly related to indebtednesses and health problems encountered in the conventional cotton system. Other reasons motivating farmers' decision to adopt organic cotton (Table 4) include: the desire to diversify their sources of income (85\% of interviewees), the willingness to make money (84\%) and to be financially independent. Thus, it clearly appears that financial reasons next to health considerations are the major determinant of farmers' decision to convert to organic cotton. This is in line with several other studies that pointed out financial reason as a major motivational factor to converting into organic in Sub-Saharan Africa context (see Ton 2002; Tulip and Ton 2002; Dowd 2008: Glin et al. 2012). However, Niemeyer and Lombard (2006) argue that financial reasons such as higher selling prices or reduced input costs are minor in the decision to adopt organic farming. In fact, producers are also concerned with their health, their environment and the fertility of their soil. For Niemeyer and Lombard (2006), in Germany, producers reported having abandoned conventional agriculture to organic farming for reasons such as: decline in farm income, soil exhaustion and soil erosion, increase in pesticide costs and aversion to the use of pesticides. For this reason Niemeyer and Lombard (2006) argue that there is a strong need for a greater national involvement in organic farming.

Table 3 Distribution of surveyed households according to their involvement in cotton production (\%)

\begin{tabular}{|c|c|c|c|c|c|}
\hline & Rich & Medium & Poor & Very poor & All \\
\hline Overall wealth distribution & 12.40 & 19.41 & 42.98 & 25.21 & 100 \\
\hline Conventional cotton & 36.70 & 29.80 & 41.30 & 41.00 & 38.40 \\
\hline Organic cotton & 46.70 & 48.90 & 33.70 & 32.80 & 38.00 \\
\hline Has left organic cotton for conventional cotton & 3.30 & 8.50 & 1.00 & 0.00 & 2.50 \\
\hline Has left conventional cotton and is not at all in cotton production & 0.00 & 0.00 & 2.90 & 6.60 & 2.90 \\
\hline Has left the organic cotton and is not at all in cotton production & 0.00 & 0.00 & 1.90 & 4.90 & 2.10 \\
\hline Has never produced cotton & 3.30 & 4.30 & 9.60 & 8.20 & 7.40 \\
\hline Production of the two type of cotton & 10.00 & 8.50 & 9.60 & 6.60 & 8.70 \\
\hline
\end{tabular}


Table 4 Other reasons for adopting organic cotton

\begin{tabular}{llllll}
\hline Reasons & Rich & Medium & Poor & Very poor & All \\
\hline Advice from neighbor/friend & 76.0 & 68.0 & 66.0 & 61.0 & 67.0 \\
To make money & 82.0 & 89.0 & 80.0 & 87.0 & 84.0 \\
Love for this activity & 29.0 & 26.0 & 30.0 & 30.0 & 29.0 \\
Learned that organic cotton is profitable & 94.0 & 75.0 & 66.0 & 78.0 & 75.0 \\
Want to do something new & 24.0 & 29.0 & 18.0 & 17.0 & 21.0 \\
In order to valorize a non-used land & 29.0 & 32.0 & 43.0 & 43.0 & 38.0 \\
Lower yields in conventional cotton & 0.0 & 18.0 & 9.0 & 9.0 & 10.0 \\
To diversify sources of income & 76.0 & 96.0 & 84.0 & 78.0 & 85.0 \\
To be financially independent & 59.0 & 78.0 & 82.0 & 87.0 & 78.0 \\
Other (to avoid debt, to protect the environment, etc.) & 47.0 & 48.0 & 34.0 & 39.0 & 40.0 \\
Achievement of objectives that motive organic cotton adoption & 100.0 & 96.0 & 88.0 & 83.0 & 91.0 \\
\hline
\end{tabular}

We focused our analysis mainly on the households involved in conventional (38\% of households interviewed) and in organic (38\% of households) cotton.

\section{Characteristics of organic cotton producers versus conventional cotton producers}

The average age of organic cotton producers is relatively higher than that of conventional cotton producers, 44 years against 41 years (Table 5). More than half of organic cotton producers are females, against only $8 \%$ of women in the conventional cotton. This is in line with Bassett's (2010: 53) argument that women are typically excluded from conventional cotton growing because of its high costs and discrimination by extension agents and men. The gender analysis of producers

Table 5 Socioeconomic characteristics of organic and conventional farmers: descriptive statistics $^{\text {(a) }}$

\begin{tabular}{|c|c|c|c|c|}
\hline & $\begin{array}{l}\text { Conventional } \\
(n=98)\end{array}$ & $\begin{array}{l}\text { Organic } \\
(\mathrm{n}=93)\end{array}$ & $\begin{array}{l}\text { Total } \\
(\mathrm{n}=191)\end{array}$ & $\begin{array}{l}\text { Statistical } \\
\text { test }^{(b)}\end{array}$ \\
\hline Age of the producer (year) & $40.5(11.5)$ & $43.5(12.5)$ & $42.0(12.0)$ & $-1.75^{*}$ \\
\hline Sex of the producer (\% of male) & 91.8 & 49.5 & 71.2 & $41.79^{* * *}$ \\
\hline Formal education of the producer (year) & $3.0(3.7)$ & $1.1(2.4)$ & $2.1(3.3)$ & $4.23^{* * *}$ \\
\hline Experience in cotton production in general (year) & $13.7(10.4)$ & $10.8(9.6)$ & $12.3(10.1)$ & $1.97^{*}$ \\
\hline Distance between the producer's house and his farm (km) & $5.0(7.4)$ & $2.5(2.0)$ & $3.8(5.6)$ & $3.20^{* * *}$ \\
\hline Household size (number of members) & $10.0(7.2)$ & $8.8(5.2)$ & $9.4(6.3)$ & 1.31 \\
\hline Land available for the household (ha) & $17.4(20.0)$ & $16.1(25.8)$ & $16.8(23.0)$ & 0.39 \\
\hline $\begin{array}{l}\text { Distance between the village and the nearest market } \\
\text { place where producer sell their products }(\mathrm{km})\end{array}$ & $6.3(8.7)$ & $8.0(11.1)$ & $7.1(9.9)$ & -1.18 \\
\hline Obtained credit (\% of yes) & 28.6 & 25.8 & 27.2 & 0.18 \\
\hline Membership of producers' organization (\% of yes) & 57.1 & 90.3 & 73.3 & $-26.84^{* * *}$ \\
\hline Contact with extension agents (\% of yes) & 60.2 & 90.3 & 74.9 & $-23.01^{* * *}$ \\
\hline $\begin{array}{l}\text { Contact with extension agents (number of visits between } \\
\text { January and October 2012) }\end{array}$ & $1.9(2.2)$ & $7.0(8.8)$ & $4.4(6.8)$ & $-5.44^{* * *}$ \\
\hline $\begin{array}{l}\text { Number of oxen owned by the producer for animal } \\
\text { traction }\end{array}$ & $1.1(2.0)$ & $0.5(1.1)$ & $0.8(1.7)$ & $2.78^{* * *}$ \\
\hline
\end{tabular}

\footnotetext{
${ }^{(a)}$ Figures in parenthesis are standard deviations;

(b) Statistical test: Pearson chi-square for dummies and t test others.

***Significant at $1 \%$, ${ }^{*}$ Significant at $10 \%$.
} 
growing organic cotton within each category of households according to the welfare status (Figure 3) also shows the dominance of females. Indeed, in $60 \%$ of the surveyed households, organic cotton is produced only by females. Intra-household analysis shows that in the class of poor households, organic cotton is produced solely by females in $29 \%$ of cases, while in $47 \%$ of cases organic cotton is practiced by both male and female. Females are also the majority among producers of organic cotton in the class of rich and medium households. In wealthy households, females and males are almost equally represented in the production of organic cotton. Overall, the predominance of females among adopters of organic cotton is interesting given that they are often the most marginalized stratum of society, with less access to land.

The level of education of organic cotton farmers is relatively low (1 year) compared to that of conventional cotton producers (3 years). Similarly, the number of years of experience in cotton production is relatively higher for producers of conventional cotton than for organic cotton producers. Conventional cotton farmers also have their farm twice far from their houses than organic cotton producers. In other words, it stands out that, compared to conventional farms, organic farms are closer to the farmer's housing (Table 5). This allows a more intense labor and eases as well the transportation of the necessary resources, particularly cow manure and organic matters which are of key importance in organic farming.

Table 5 also indicates that household size of conventional cotton producers is higher than that of households of organic cotton farmers. This also applies to the total area available. However, the difference between the two groups is not significant at $5 \%$ level.

Almost $27 \%$ of respondents have access to credit, with about $29 \%$ for conventional cotton producers against $26 \%$ for organic cotton producers. $90 \%$ of organic cotton producers are members of a cooperative against $57 \%$ for producers of conventional cotton. This indicates that organic farmers are better organized and have more contacts with advisory and extension services. The organic cotton producers also have more access to extension services than conventional cotton farmers.

Overall, we can retain that conventional cotton producers are mainly men with relatively more productive resources (available land, labor, oxen) unlike organic cotton households. However, they are relatively younger and have their farms two times far from their houses compared to organic cotton producers.

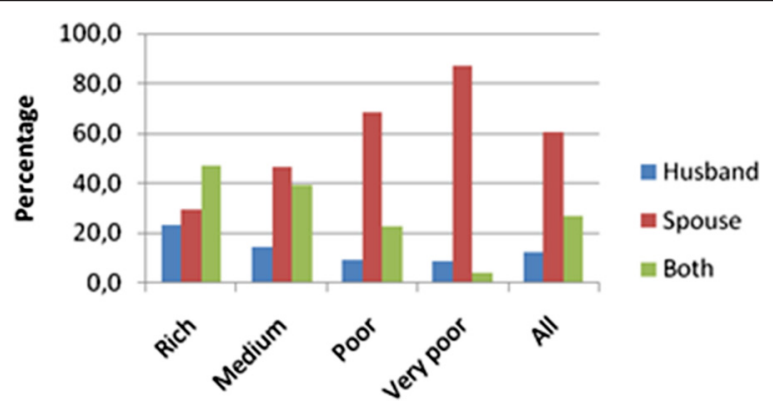

Figure 3 Gender of the member producing organic cotton in the household of organic cotton farms. 


\section{Farmers' characteristics and organic cotton adoption}

The results of the probit model are presented in Table 6. It is worth noting that in our initial probit model, the squared of the variable $\mathrm{AGE}\left(\mathrm{AGE}^{2}\right)$ and the squared of the distance between producers' house and their farms $\left(\right.$ DISTEX $\left.^{2}\right)$ had no significant effects on the adoption of organic cotton farming. Indeed, the Likelihood Ratio (LR) tests indicated that these two variables had no significant influence of the adoption of organic cotton. ${ }^{\mathrm{c}}$ Thus, we re-estimated the probit model without these two variables.

Table 6 indicates that producers' age positively influences the adoption of organic cotton. In other words, older farmers are more likely to adopt organic cotton than younger producers. The probability that a producer adopts organic cotton increases, ceteris paribus, by 1.0 percentage point when farmer's age increases by one year. This result is contrary to the findings of several authors (Duram 1997; Marenya and Barrett 2007; Läpple and Van Rensburg 2011; see also Niemeyer and Lombard 2006) who argued that younger farmers are more open to the adoption of organic farming than older farmers.

Gender significantly influences the adoption of organic cotton. The probability of organic cotton adoption tends to be, ceteris paribus, 49 percentages points higher for female farmers. This indicates that organic farming is more attractive to women compared to conventional farming. In fact, organic cotton farming enables women to hold a separate cotton farm and thus increase their economic independence, whereas with the conventional system they depend mainly on the farm of the (male) head of the household (Glin et al. 2012: 344; see also Tovignan 2005). The use of inputs locally available is also key factor that foster women decision to practice organic farming (Assogba et al., 2014). In most cases, females also perform more effectively in organic farming than males because their farms are smaller in size and often closer to the compounds. This eases the mobilization of organic inputs as well as the provision of the necessary cares and the overall management of the organic farm. This corroborates the findings of Bjørkhaug (2006), for whom male-headed farms tend to be large with a strong commercial focus, while women-headed farms tend to be smaller in size, with lower output volume and higher contribution of off-farm income to total farm income. Moreover, women are particularly concerned with the health effects of the highly toxic pyrethroid insecticides used in conventional cotton farms (Bassett 2010). There is a belief that toxic chemical products affect woman fertility and fetal development in case of pregnancy. All this in addition to the high inputs cost and discrimination in conventional (cotton) farming system makes organic the best and preferred option for women.

In addition, contrary to our expectation, the probability that a farmer adopts organic cotton tends to be, ceteris paribus, 5 percentage points higher when the level of education drops a unit (Table 6). This means that less educated farmers are more likely to adopt organic cotton farming than highly educated farmers. This result is contrary to those generally available in earlier studies of the adoption of organic farming (e.g., Demiryurek 2010; Mzoughi 2011) where education often has a significant positive effect on organic farming adoption. For Läpple and Van Rensburg (2011) the level of education has no significant effect on the adoption of organic farming. Our result is however in line with Burton et al. (2003). According to this author the negative effect of education on organic farming adoption may be due to differences in country and commodity coverage. In Benin, the level of education is relatively low in rural 
Table 6 Determinants of organic cotton adoption: results of the probit model

\begin{tabular}{|c|c|c|c|}
\hline Variable & Label & Coefficient $^{(\mathrm{a})}$ & Marginal effect ${ }^{(\mathrm{a})(\mathrm{b})}$ \\
\hline AGE & Age of the producer (year) & $0.025^{*}(0.014)$ & $0.010^{*}(0.005)$ \\
\hline SEX & Sex of the producer ( $1=$ male, $0=$ female) & $-1.542^{* * *}(0.441)$ & $-0.490^{* * *}(0.107)$ \\
\hline EDUC & Formal education of the producer (year) & $-0.118^{* *}(0.053)$ & $-0.046^{* *}(0.021)$ \\
\hline EXPCOT & Experience in cotton production in general (year) & $-0.034^{*}(0.021)$ & $-0.013^{*}(0.008)$ \\
\hline CLASSP & Class of poverty as perceived by producers ( $1=$ very poor, $2=$ poor, $3=$ medium, $4=$ rich) & $-0.102(0.206)$ & $-0.039(0.080)$ \\
\hline CENTRE & Regional dummy ( $1=$ Farmers located in the Centre of Benin, $0=$ otherwise $)$ & $1.346^{* *}(0.641)$ & $0.451^{* * *}(0.173)$ \\
\hline NORTHW & Regional dummy ( $1=$ Farmers located in the northwest-Benin, $0=$ otherwise $)$ & $-0.318(0.473)$ & $-0.124(0.185)$ \\
\hline LNDISTEX & Logarithm of the distance between the producer's house and his farm (km) & $-1.112^{* * *}(0.326)$ & $-0.431^{* * *}(0.126)$ \\
\hline HHSIZE & Household size (number of members) & $0.052^{*}(0.031)$ & $0.020^{*}(0.012)$ \\
\hline LNSUPTOT & Logarithm of the amount of land available (ha) & $-0.235(0.237)$ & $-0.091(0.092)$ \\
\hline OXEN & Ownership of oxen ( 1 =yes) & $0.452(0.572)$ & $0.168(0.202)$ \\
\hline LNDISTM & $\begin{array}{l}\text { Logarithm of the distance between the village and the nearest market place where producer } \\
\text { sell their products }(\mathrm{km})\end{array}$ & $0.075(0.117)$ & $0.029(0.045)$ \\
\hline ACRED & Obtained credit $(1=$ yes, $0=$ no $)$ & $-0.340(0.341)$ & $-0.133(0.134)$ \\
\hline COOP & Membership of producers' organization ( 1 =yes) & $0.554(0.371)$ & $0.217(0.144)$ \\
\hline NVISIT & Contact with extension agents (number of visits between January and October 2012) & $0.355^{* * *}(0.073)$ & $0.138^{* * *}(0.026)$ \\
\hline CONS & Constant & $0.192(0.738)$ & \\
\hline
\end{tabular}

Number of observation $=191 ; \operatorname{LR}$ chi2 $(14)=144.43^{* * *}, \log$ likelihood $=-60.110$, Pseudo $R 2=0.5457$.

${ }^{(a)}$ Figures in parenthesis are standard errors; ${ }^{(b)}$ The partial derivative is given by $\frac{\partial E[y \mid x]}{\partial x}=\phi\left(x^{\prime} \beta\right) \beta$ continue variables and $\operatorname{Prob}\left[y=1 \mid \bar{x}_{(d)}, d=1\right]-\operatorname{Prob}\left[y=1 \mid \bar{x}_{(d)}, d=0\right]$, for dummy variables $(G r e e n e 2008: 775)$, with $\bar{x}_{(d)}$ the means of all the other variables in the model.

*** Significant at $1 \%$, ** Significant at $5 \%$, ${ }^{*}$ Significant at $10 \%$. 
areas; and the educated people living in cotton production areas are generally involved in the management of conventional cotton producers' cooperative (Alidou, 2014). They are relatively rich and can hardly accept losing the privileges and the social prestige associated with the management of conventional cotton cooperatives (see also Alidou, 2014).

The negative effect of the level of education on the decision to produce organic cotton could probably be linked to the fact that more than half of organic producers in the sample are women. To test this, we re-estimated the probit model separately for females and for males. The results obtained and presented in Table 7 indicate that the level of education has a negative influence on the adoption of organic cotton for males and for females. However, the influence of education on the adoption of organic cotton is not statistically significant for females $(p>0.10)$ while it is significant for males. In short, the negative effect of the level of education on the adoption of organic cotton is not due to the fact that more than half of organic producers in the sample are women.

In the same vein, there is a negative (but insignificant) relationship between the adoption of organic cotton and the level of household wealth (Table 6). This means that poor farmers and wealthier peasants have almost the same probability to adopt organic cotton farming. Thus, beyond the poverty level, there are other factors that lead farmers to become organic cotton producer. For example, Moumouni et al. (2013) argued that beyond profitability, attitudinal aspects and social dynamics (in the household and the society) also influence producers' decisions to adopt organic farming methods. Although poor and rich farmers have statistically the same likelihood to adopt the

Table 7 Determinants of organic cotton adoption: results of the probit model for women and men

\begin{tabular}{|c|c|c|c|}
\hline Variables & Label & $\begin{array}{l}\text { Women } \\
\text { Coefficient }^{(a)}\end{array}$ & $\begin{array}{l}\text { Men } \\
\text { Coefficient }^{(a)}\end{array}$ \\
\hline AGE & Age of the producer (year) & $0.044(0.034)$ & $0.025(0.017)$ \\
\hline EDUC & Formal education of the producer (year) & $-0.144(0.401)$ & $-0.118^{* *}(0.057)$ \\
\hline EXPCOT & Experience in cotton production in general (year) & $-0.010(0.055)$ & $-0.043^{*}(0.026)$ \\
\hline CLASSP & $\begin{array}{l}\text { Class of poverty as perceived by producers }(1=\text { very poor, } \\
2=\text { poor, } 3=\text { medium, } 4=\text { rich })\end{array}$ & $-0.343(0.554)$ & $-0.059(0.233)$ \\
\hline CENTRE & $\begin{array}{l}\text { Regional dummy }(1=\text { Farmers located in the Centre of } \\
\text { Benin, } 0=\text { otherwise) }\end{array}$ & & $1.327^{*}(0.741)$ \\
\hline NORTHW & $\begin{array}{l}\text { Regional dummy ( } 1=\text { Farmers located in the northwest-Benin, } \\
0=\text { otherwise) }\end{array}$ & $-0.693(0.852)$ & $-0.895(0.901)$ \\
\hline LNDISTEX & $\begin{array}{l}\text { Logarithm of the distance between the producer's house } \\
\text { and his farm }(\mathrm{km})\end{array}$ & $-1.487(1.208)$ & $-1.077^{* * *}(0.355)$ \\
\hline HHSIZE & Household size (number of members) & $0.162(0.138)$ & $0.044(0.035)$ \\
\hline LNSUPTOT & Logarithm of the amount of land available (ha) & $0.158(0.463)$ & $-0.257(0.290)$ \\
\hline OXEN & Ownership of oxen ( 1 = yes) & & $0.930(0.899)$ \\
\hline LNDISTM & $\begin{array}{l}\text { Logarithm of the distance between the village and the nearest } \\
\text { market place where producers sell their products }(\mathrm{km})\end{array}$ & $-0.087(0.248)$ & $0.137(0.141)$ \\
\hline ACRED & Obtained credit $(1=$ yes, $0=$ no $)$ & $-0.407(0.965)$ & $-0.369(0.399)$ \\
\hline COOP & Membership of producers' organization (1 = yes) & $0.998(0.661)$ & $0.440(0.528)$ \\
\hline NVISIT & $\begin{array}{l}\text { Contact with extension agents (number of visits between } \\
\text { January and October 2012) }\end{array}$ & $0.447^{*}(0.236)$ & $0.370^{* * *}(0.083)$ \\
\hline CONS & Constant & $-0.805(1.730)$ & $-1.232(0.880)$ \\
\hline
\end{tabular}

${ }^{(a)}$ Figures in parenthesis are standard errors;

***Significant at $1 \%,{ }^{* *}$ Significant at $5 \%,{ }^{*}$ Significant at $10 \%$. 
organic cotton, Lapple (2010) argued that, when these low-income farmers convert to organic farming they are more likely to continue in the future. Giovannucci et al. (2005) explained low-income farmers' attitudes by the fact that organic cotton production is almost an effective risk management tool that reduces their input costs, and provides them improved income.

Finally, it stands out that the adoption of organic cotton significantly depends on the number of years that the producer spent in (conventional) cotton farming (Table 6). In other words, farmers with few years of experience in cotton in general tend to adopt organic cotton. Thus, the probability that a farmer adopts organic cotton tends to be, ceteris paribus, about 1 percentage point higher when the number of years of experience in cotton in general drops a unit.

\section{Effect of farm and biophysical factors on organic cotton adoption}

The variable NORTHW has no significant effect on the adoption of organic cotton, whereas variable CENTRE significantly influences the adoption of organic farming. The producers of Center-Benin are much more likely to adopt organic cotton than producers of the two other regions (Northwest-Benin and Northeast-Benin). Thus, as the variable CENTRE also control for land pressure, one can say that farmers who live in areas with low human pressure on land are more likely to adopt the organic farming than their counterpart farmers who live in areas with high human land pressure. In other words, the probability that producers of Centre-Benin (area with low human pressure on land) adopt organic cotton is, ceteris paribus, 45 percentage points higher than the producers of two other regions.

Producers who have their farm near home are more likely to adopt organic farming than those who have the farm far from their homes. This is due to the fact that producers who have their farm close to their house have less difficulty to transport organic fertilizers and other inputs used in the organic cotton production. The probability that farmers adopt the organic cotton is 4.3 percentage points higher when they live a kilometer close to farm.

It also came out that household size has a positive and significant effect $(p>0.10)$ on the adoption of organic cotton. This can be explained by the fact that organic cotton production is more labor-intensive than conventional cotton. Put differently, this reflects the importance of family labor in the adoption of organic farming given resource-poor farmers have financial constraints for hiring wage laborers (Marenya and Barrett 2007). As a result, farmers with relatively large amount of labor are more likely to engage in organic cotton farming.

Finally, the area of land available for the household has a negative (but insignificant) influence on the adoption of organic cotton. The analysis of the land area under cotton production indicates (Table 8) that the area under conventional cotton is almost the double of that of organic cotton. Likewise, within the different classes of prosperity, the area cultivated in conventional cotton is higher than in organic cotton. For instance, in the class of rich households, the average size in conventional cotton is almost the triple of organic cotton. Whatever the level of prosperity, organic cotton farmers grow less than 10 ha (Table 8). Most of the organic farmers (78.6\%) grow less or not more than 2 ha of cotton. This is particularly true for farmers of very poor conditions. In the class 
Table 8 Amount of land under organic and conventional cotton

\begin{tabular}{rlllll}
\hline Type of cotton farming & Rich & Medium & Poor & Very poor & All \\
\hline $\begin{array}{c}\text { Conventional cotton (ha) }{ }^{(\mathrm{a})} \\
\text { Distribution (\%) }\end{array}$ & $8.63(10.64)$ & $3.23(2.28)$ & $2.75(2.09)$ & $1.64(1.21)$ & $3.30(4.59)$ \\
{$[0,2]$ ha } & 20.0 & 42.9 & 57.4 & 86.2 & 57.1 \\
{$[2,5]$ ha } & 33.3 & 42.9 & 33.3 & 10.3 & 29.4 \\
] $5,10]$ ha & 26.7 & 14.3 & 9.3 & 3.4 & 10.9 \\
$>10$ ha & 20.0 & 0.0 & 0.0 & 0.0 & 2.5 \\
Organic cotton (ha) $)^{(a)}$ & $3.21(2.17)$ & $2.60(1.98)$ & $0.79(0.72)$ & $0.56(0.37)$ & $1.56(1.73)$ \\
Distribution $(\%)$ & & & & & \\
{$[0,2]$ ha } & 41.2 & 53.6 & 97.7 & 100.0 & 78.6 \\
] $2,5]$ ha & 47.1 & 35.7 & 2.3 & 0.0 & 17.0 \\
]5, 10] ha & 11.8 & 10.7 & 0.0 & 0.0 & 4.5 \\
$>10$ ha & 0.0 & 0.0 & 0.0 & 0.0 & 0.0 \\
\hline
\end{tabular}

${ }^{(a)}$ Figures in parenthesis are standard deviations.

of medium households, more than half of organic cotton producers grow less than 2 ha of cotton. Overall, it stands out that (i) the area under organic cotton is positively associated with the level of wealth of households, with the area under cotton for the rich being almost six times that of the poorest; (ii) the average size produced in conventional cotton is almost the double of that produced in organic cotton. The reason of this is twofold. First, organic cotton farming is more labor-intensive than conventional cotton and can only be adequately handled on relatively small scale, particularly due to the weeding process. Secondly, organic farming relies mainly on natural resources and materials (cow manure, neem seeds, etc.) for soil fertility and pest management and it is difficult to mobilize enough for a large size of operation. The same situation is observed for organic agriculture in countries like Canada, New Zealand and the USA (see Niemeyer and Lombard 2006).

Finally, it is worth noting that the ownership of oxen and "the distance between the village and the nearest market place where producers sell their produce" have no significant effect $(p>0.10)$ on the organic cotton adoption.

\section{Effect of institutional and economic factors on organic cotton adoption}

The institutional factors considered include: access to credit, support from extension services, and membership in farmer's association.

It came out that access to credit has no significant influence on the adoption of organic cotton, meaning that credit is not a determinant factor in the dissemination of organic cotton (Table 6). In fact, organic farming is less dependent on marketed inputs compared to conventional cotton farming. Moreover, there is no credit incentive in the institutional support provided by the several organic cotton programs in Benin. Furthermore, because of the indebtedness they witnessed in the conventional cotton system, most of the organic farmers are more suspicious about credit.

With respect to support from extension services, the number of visits of extension agents is positively and significantly associated with the adoption of organic cotton farming. Organic cotton farmers benefit from intensive extension services from NGOs 
and development organizations, which are the major drivers of organic value chains in Benin and in West Africa in general. This confirms our expectations regarding the effect of extension on the adoption of organic cotton. Indeed, organic farming is knowledge intensive and requires regular interactions between farmers and extension services.

Membership in a farmers' cooperative has positive but insignificant effect on the adoption of organic cotton (Table 6). In other words, the decision to engage in the production of organic cotton is not dependent on whether the producer belongs to a cooperative or not. However, although membership in cooperatives has no significant influence on the adoption of organic cotton, various studies have highlighted the importance of cooperatives and other farmer associations in the adoption of innovations. Thus, Sodjinou and Henningsen (2012) showed that cooperatives are not only channels for the dissemination of innovations but also institutions where producers share the innovations and the various problems encountered. Indeed, "joint problem solving, and farmer-to-farmer exchange can improve community relations and lead to greater involvement and commitment of producers" (Giovannucci et al. 2005). Accordingly, as noted by Giovannucci et al. (2005), farmers' organizations could be considered as a central aspect of a strategy aimed at using organic agriculture as a tool for poverty alleviation in rural areas.

Basically, organic farming is 'knowledge intensive' and requires the mobilization and building of effective socio-technical networks allowing interactive and social learning among peer organic farmers, extension and advisory services, and even research organizations (van Elzakker 1999; Glin et al. 2012; Moumouni et al. 2013; Nicolay and Baker 2012). Besides, the social control and internal control systems that are at the heart of the certification mechanism of organic farming require collective action to control the traceability of materials and resources used (sprays equipments, organic inputs, etc.) and ensure the compliance with the organic standard.

\section{Conclusion}

The objective of this study was to assess socioeconomic and institutional factors determining farmers' decisions to adopt organic cotton. In fact, the organic cotton initiative was developed as an alternative to the environmental, health, and socioeconomic concerns of conventional cotton farming with its high reliance on chemicals. Thus, the organic agenda may well fit in the current policy debate on green economy, climate smart agriculture and resilience by reconciling economic development with environmental and social principles. In Benin, the government is strongly concerned with the fulfillment of the Millennium Development Goals, particularly halving poverty while sustaining environment and natural resources. From the results of this study, it clearly appears that organic cotton farming is more attractive to women, older, less educated, and poorer producers, all those being the most vulnerable categories in society. Subsequently, organic cotton should be considered as a prospective policy option to reach the poor and strengthen their livelihoods conditions while contributing to preserve the environment and natural resources. According to FAO (2010), increased investments in agricultural development targeting the smallholder farmers in developing countries is an important element in improving food security in rural areas. Moreover, the increasing trends of 
chemical inputs (pesticides and mineral fertilizers) costs in the context of uncertainty and a fragile global economy make the organic cotton a refuge to protect vulnerable farmers against external shocks. Furthermore, organic farming enables women to hold a separate cotton farm and thus increase their economic independence contrary to the conventional system where they depend mainly on the farm of the (male) head of the household.

Lastly, the institutional factors that determine the adoption of organic cotton include mainly the support from extension services and to some extent farmers' membership in cooperatives. Despite the relative strength of the organic cotton system in these areas, there is still a need to enhance the extension system by: (1) exploring, designing, and upgrading innovative pedagogic tools such as videos and mobile phone technology to foster learning; and (2) strengthening organic farmer's organizations and the linkage with agricultural research organizations for technology development.

\section{Endnotes}

a The decline in organic cotton production in 2010 is due to the unsuccessful marketing over the years 2008 and 2009 saw organic farmers being paid later than conventional ones, which created distrust among many organic farmers and quite a few subsequently withdrew from organic cotton production during the year 2009/2010 (Glin et al. 2012).

${ }^{b}$ Pressure on land means overuse of agricultural land, and also high/increased demand of land for agriculture. The land available is not often sufficient to satisfy the increased demand.

${ }^{\mathrm{c}}$ For the test of the variable AGE2, LR chi2 $=0.00$ (with P-val $=0.987$ ), and For the test of the variable DISTEX2, LR chi2 $=2.75$ (with P-val $=0.097$ ).

Competing interests

The authors declare that they have no competing interests.

\section{Authors' contributions}

All authors: conceived the study, involved in its design and participated in field data collection. ES: prepared the data, performed the statistical analysis. ES and LCG drafted the manuscript together. NG: read and commented the first draft. All authors read and approved the final manuscript.

\section{Author details}

${ }^{1}$ Ecole Nationale des Sciences et Techniques Agronomiques de Djougou, Université de Parakou, 03 BP 412 , Porto-Novo, République du Benin. ${ }^{2}$ FiBL West Africa, BP 16 IER/CRRA Sikasso, République du Mali. ${ }^{3}$ FiBL (Research Institute of Organic Agriculture), 5070 Frick, Switzerland. ${ }^{4}$ Faculté d'Agronomie, Université de Parakou, Parakou, République du Benin. ${ }^{5}$ Institut National des Recherches Agricoles du Benin, Natitingou, République du Benin.

Received: 31 December 2013 Accepted: 5 March 2015

Published online: 15 April 2015

References

Alidou GM (2014) Networking, Social Capital and Gender Roles in the Cotton System in Benin. Wageningen University, Dissertation

Assogba SC-G, Tossou RC, Lebailly P, Magnon Y (2014) Sustainable intensification of agriculture in Benin: myth or reality? Lessons from organic and cotton made in Africa production systems. Int J Agric Innovation Res 2(5):2319-1473

Baffes J (2007) The "cotton problem" in West and Central Africa: the case for domestic reforms. CATO Institute. Econ Dev Bull No. 11. Available via http://www.cato.org/pubs/edb/edb11.html. Accessed 30 Dec 2013

Bassett T (2010) Slim pickings: fairtrade cotton in West Africa. Geoforum 41(1):44-55

OBEPAB (Organisation Béninoise pour la Promotion de l'Agriculture Biologique, 2002) Le Coton au Bénin: rapport de consultation sur le coton conventionnel et le coton biologique au Bénin. PAN UK's Pesticides, Poverty and Livelihoods project. Available via http://www.pan-uk.org/Projects/Cotton/pdfs/Benin.pdf. Accessed 29 Dec 2013.

Bjørkhaug $\mathrm{H}$ (2006) Is there a female principle in organic farming? An interpretation of data for Norway. In: Holt G, Reed M (eds) Sociological Perspectives of Organic Agriculture: From Pioneer to Policy. CAB International, London, pp 195-209

Bolwig S, Gibbon P, Jone S (2009) The economics of smallholder organic contract farming in tropical Africa. World Dev 37(6):1094-1104

Burton M, Rigby D, Young T (2003) Modelling the adoption of organic horticultural technology in the UK using duration analysis. Australian J Agr Resource Econ 47(1):29-54 
Chilonda P, van Huylenbroeck G (2001) A conceptual framework for the economic analysis of factors influencing decision-making of small-scale farmers in animal health management. Rev sci tech Off int Epiz 20(3):687-700

Demiryurek K (2010) Analysis of information systems and communication networks for organic and conventional hazelnut producers in the Samsun province of Turkey. Agr Syst 103:444-452

Doss CR (2006) Analyzing technology adoption using microstudies: limitations, challenges, and opportunities for improvement. Agric Econ 34:207-219

Doss CR, Morris ML (2001) How does gender affect the adoption of agricultural innovations? The case of improved maize technology in Ghana. Agric Econ 25:27-39

Doss CR, Mwangi W, Verkuijl H, de Groote H (2003) Adoption of Maize and Wheat Technologies in Eastern Africa: A Synthesis of the Findings of 22 Case Studies. CIMMYT Economics Working Paper 03-01. Mexico: CIMMYT

Dowd B (2008) Organic Cotton in Sub-Saharan Africa. A new Development Paradigm? In: Moseley W, Gray L (eds) Hanging by a Thread: Cotton, Globalization and Poverty in Africa. Ohio University Press, Athens, OH, pp 251-271

Duram A (1997) A pragmatic study of conventional and alternative farmers in Colorado. Prof Geogr 49(2):202-213

Eyhorn F, Ramakrishnan M, Mader P (2007) The viability of cotton-based organic farming systems in India. Int J Agric Sustain 5(1):25-38

FAO (2010) The State of Food Insecurity in the World 2010, Addressing Food Insecurity in Protracted Crises. Food and Agriculture Organization of the United Nations, Rome

Ferrigno S, Ratter SG, Ton P, Vodouhê DS, Williamson S, Wilson J (2005) Organic cotton: a new development path for African smallholders? The Gatekeeper Series, 23p.

Gbesso CA (2000) Etude comparée de la rentabilité socioéconomique du coton biologique et du coton conventionnel. Université d'Abomey-Calavi, Mémoire de Maitrise

Gergely N (2009) The Cotton Sector of Benin. World Bank, Washington

Giovannucci D, Eyhorn F, Han Z, Joensen L, John M, Mehta S, Meng F, Ramakrishnappa K, Reddy SST, Thimmaiah A Xi Y, Zong H (2005) Organic agriculture and poverty reduction in Asia: China and India Focus. IFAD Office of Evaluation, Rome. Available via http://www.ifad.org/evaluation/public_html/eksyst/doc/thematic/organic/asia.pdf. Accessed 31 Dec 2013.

Glin L C (2014) Governance of global organic agro-food networks from Africa. PhD thesis, Wageningen University, the Netherlands.

Glin LC, Mol APJ, Oosterveer P, Vodouhê DS (2012) Governing the transnational organic cotton network from Benin. Global Netw 12(3):333-354

Glin LC, Mol APJ, Oosterveer P (2013) Conventionalization of the organic sesame network from Burkina Faso: shrinking into mainstream. Agric Hum Values 30(4):539-554

Greene WH (2008) Econometric Analysis, 6th edn. Pearson, Upper Saddle River NJ

Guilmo E Navarro E, Ribet C, Stanicka L, Vaugeois M (2006). Coton Bio ou coton Bt : Une solution pour les paysans pauvres? 11p., Available: http://www.museum.agropolis.fr/pages/savoirs/cotontransgenique/rapport_controverse. pdf. Accessed 16 Nov 2014.

Hole DG, Perkins AJ, Wilson JD, Alexander IH, Grice PV, Evans AD (2005) Does organic farming benefit biodiversity? Biol Conserv 122:113-130

Hulsebusch C, Wichern F, Hemann H, Wolff P (eds) (2007) Organic agriculture in the tropics and subtropics current status and perspectives. Supplement No 89, J Agr Rural Dev Trop. Kassel University Press GmbH. Available via http://www.uni-kassel.de/upress/online/frei/978-3-89958-263-5.volltext.frei.pdf. Accessed 31 Dec 2013.

Justus O (2009) Value Chain Analysis of Organic Cotton Sub sector in Tanzania. Department of Agricultural Economics and Agribusiness Management, Egerton University, Kenya. Avaible via http://www.iiste.org/Journals/index.php/DCS/ article/viewFile/14424/14733. Accessed 27 Aug 2014

Kristiansen P, Taji A, Reganold J (2006) Organic Agriculture: A Global Perspective. CABI Publishing, Wallingford

Kutting G (2004) Globalization and the Environment: Greening Global Political Economy. State University of New York Press, Albany

Lapple D (2010) Adoption and abandonment of organic farming: an empirical investigation of the Irish Drystock Sector. J Agr Econ 61(3):697-714

Läpple D, Van Rensburg T (2011) Adoption of organic farming: are there differences between early and late adoption? Ecolog Econ 70:1406-1414

Lockie S, Lyons K, Lawrence G, Halpin D (eds) (2006) Going Organic: Mobilizing Networks for Environmentally Responsible Food Production. CABI, Oxfordshire and Cambridge

MAEP (Ministère de l'Agriculture de l'Elevage et de la Pêche (2011) Plan stratégique de relance du secteur agricole (PSRSA) au Bénin. MAEP, Cotonou

Marenya PP, Barrett CB (2007) Household-level determinants of adoption of improved natural resources management practices among smallholder farmers in western Kenya. Food Pol 32:515-536

Matthess A, van den Akker E, Chougourou D, Midingoyi S (2005) Compétitivité et durabilité de cinq systèmes culturaux cotonniers dans le cadre de la filière. GTZ-MAEP, Cotonou

Moseley WG, Gray LC (2008) Hanging by a Thread: Cotton, Globalization, and Poverty in Africa. Ohio University Press, Athens, $\mathrm{OH}$

Moumouni MI, Baco MN, Tovignan S, Gbèdo F, Nouatin GS, Vodouhê SD, Liebe U (2013) What happens between technico-institutional support and adoption of organic farming? A case study from Benin. Organic Agriculture. DOI 10.1007/s13165-013-0039-x.

Mzoughi N (2011) Farmers adoption of integrated crop protection and organic farming: Do moral and social concerns matter? Ecolog Econ 70:1536-1545

Negatu W, Parikh A (1999) The impact of perception and other factors on the adoption of agricultural technology in the Moret and Jiru Woreda (district) of Ethiopia. Agric Econ 21:205-216

Nicolay G, Baker B (2012) Challenges and opportunities for organic research and extension. Rural 21-03/2012. Available via http://orgprints.org/23505/1/rural2012_03-S32-34.pdf. Accessed 29 Dec 2013.

Niemeyer KB, Lombard JP (2006) Emerging Scared: An Analysis of Socioeconomic Data on Conversion in South Africa. In: Holt G, Reed M (eds) Sociological Perspectives of Organic Agriculture: From Pioneer to Policy. CAB International, London 
Pacini C, Wossink A, Giesen G, Vazzana C, Huirne R (2002) Evaluation of sustainability of organic, integrated and conventional farming systems: a farm and field-scale analysis. Agric Ecosyst Environ 95:273-288

Pazou EYA, Boko M, van Gestel CAM, Ahissou H, Lalèyè P, Akpona S, van Hattum B, Swart K, van Straalen NM (2006a) Organochlorine and organophosphorous pesticide residues in the Ouémé River catchment in the Republic of Bénin. Environ Int 32:616-623

Pazou EYA, Lalèyè P, Boko M, van Gestel CAM, Ahissou H, Akpona S, van Hattum B, Swart K, van Straalen NM (2006b) Contamination of fish by organochlorine pesticide residues in the Ouémé River catchment in the Republic of Bénin. Environ Int 32:594-599

Polson RA, Spencer DSC (1991) The technology adoption process in subsistence agriculture: the case of cassava in southwestern Nigeria. Agr Syst 36:65-78

Ranjani KM, Sagayam J, Sudha N, Rengalakshmi R (2008) Gender, efficiency, poverty reduction, and empowerment: reflections from an agriculture and credit programme in Tamil Nadu, India. Gene Dev 16(1):101-116

Rogers EM (2003) Diffusion of Innovations, 5th edn. The Free Press, New York

Sall S, Norman D, Featherstone AM (2000) Quantitative assessment of improved rice variety adoption: the farmer's perspective. Agr Syst 66:129-144

Sarker A, Itohara Y (2008) Factors influencing the extent of practice of organic farming technologies: a case study of Tangail district in Bangladesh. Am J Agr Biol Sci 3(3):584-590

Skinner C, Gattinger A, Muller A, Mäder P, Fliessbach A, Stolze M, Niggli U (2014) Greenhouse gas fluxes from agricultural soils under organic and non-organic management: A global meta-analysis. Sci Total Environ 468-469: $553-563$

Sodjinou E (2011). Poultry-based intervention as tool for poverty reduction and gender empowerment: empirical evidence from Benin. Dissertation, University of Copenhagen. Available via http://curis.ku.dk/ws/files/33324451/Thesis_Sodjinou_ February_2011_VF.pdf. Accessed 01 June 2013.

Sodjinou E, Henningsen A (2012) Community-based management and interrelations between different technology adoption decisions: innovations in village poultry farming in Western Africa. FOI Working Paper 2012/11. Institute of Food and Resource Economics, Copenhagen. Available via http://okonomi.foi.dk/workingpapers/WPpdf/WP2012/ WP_2012_11_village_poultry_farming.pdf. Accessed 01 June 2013.

Ton P (2002) Organic Cotton Production in Sub-Saharan Africa: The Need of Scaling up. Pesticide Action Network, London

Ton G, Bijman J, Oorthuizen J (2007) Introduction. In: Ton G, Bijman J, Oorthuizen J (eds) Producer Organizations and Market Chains: Facilitating Trajectories of Change in Developing Countries. Wageningen Academic Publishers, Arnhem, pp 11-19

Tovignan DS (2005) Gender Perspectives in the Adoption of Organic Cotton in Benin: A Farm Household Modeling Approach. University Of Giessen, Dissertation

Tulip A, Ton P (2002) Organic Cotton Study: Uganda Case Study. Pesticide Action Network, London

van Elzakker B (1999) Organic Cotton Production. In: Myers D, Stolton S (eds) Organic Cotton: From Field to Final Product. Intermediate Technology Publications, London

Verbeek M (2004) A Guide to Modern Econometrics, 2nd edn. John Wiley \& Sons Ltd, West Sussex

\section{Submit your manuscript to a SpringerOpen ${ }^{\circ}$ journal and benefit from:}

- Convenient online submission

- Rigorous peer review

- Immediate publication on acceptance

- Open access: articles freely available online

- High visibility within the field

Retaining the copyright to your article 